\title{
The Efficacy of Mindfulness-Based Cognitive Therapy on Self-Efficacy and Anxiety Among Epileptic Patients
}

\author{
Samaneh Mohamadpour, ${ }^{1}$ Fakhri Tajikzadeh, ${ }^{1,}$ and Abdolaziz Aflakseir ${ }^{2}$ \\ ${ }^{1} \mathrm{PhD}$ Student in Shiraz University, Shiraz, IR Iran \\ ${ }^{2}$ Associate Professor of Clinical Psychology, Shiraz University, Department of Clinical Psychology, Shiraz, IR Iran \\ "Corresponding author: Fakhri Tajikzadeh, Department of Education and Psychology, Shiraz University, Shiraz, IR Iran. Tel: +98-9173286298, E-mail: f.tajikzade@shirazu.ac.ir
}

Received 2016 May 15; Revised 2016 December 10; Accepted 2017 January 07.

\begin{abstract}
Objective: The aim of the present study was to investigate the efficacy of mindfulness-based cognitive therapy (MBCT) on selfefficacy and anxiety among epileptic patients.

Methods: The present study with a pretest-posttest control-group design was performed on epileptic patients in public healthcare centers of Kuhdasht, Iran. Through randomized sampling, 15 patients were selected for the experimental group and 15 epileptic patients for the control group. The experimental group received MBCT once a week during 8 sessions, while the control group was engaged in usual activities. The data collection tools included the general self-efficacy scale (GSES) and Zung self-rating anxiety scale (SAS). For statistical analysis, descriptive tests and repeated measures analysis of variance were performed.

Results: Data analysis showed significant differences in self-efficacy and anxiety scores between the experimental and control groups $(\mathrm{P}<0.001)$.
\end{abstract}

Conclusions: According to the results, MBCT can increase self-efficacy and decrease anxiety in epileptic patients.

Keywords: Mindfulness-Based Cognitive Therapy, Self-efficacy, Anxiety, Epilepsy

\section{Background}

The prevalence of epilepsy has been reported to be $1 \%$ worldwide (1). Epileptic patients experience various psychological problems (2). The overall prevalence of psychiatric disorders in epileptic patients has been reported to be $50 \%-60 \%$ (3). Patients with epilepsy often encounter various challenges while performing work-related tasks or daily activities and normally experience low functionality, social isolation, and psychological distress (4).

Psychiatric disorders have a negative impact on the quality of life, occupation, and interpersonal relationships of epileptic patients, and disorders, such as depression and anxiety, remain common among these patients (5). Anxiety can reduce the quality of life in epileptic patients and is associated with other problems (3). Anxiety associated with epilepsy affects not only adults, but also children, causing more pain and problems persisting into adulthood (6).

According to previous studies, self-efficacy determines the level of basic self-management in epileptic patients. In fact, patients with a high level of self-management and self-care are more successful and efficient in controlling their medications. In addition, they are more successful in avoiding aggravating symptoms and reviewing their health status (7-9).

Self-efficacy is one's belief in his/her competence to successfully carry out a particular task or achieve a particular purpose (4). It is an important element in the management of epileptic children and facilitates psychosocial compatibility of the patients. Low levels of self-efficacy in seizure management of epileptic patients have a significant relationship with negative attitudes toward epilepsy, concerns about seizures and attacks with greater severity, less family support and management, and more depressive symptoms. In addition, self-efficacy is self-management of the behavioral outcomes of epilepsy among patients (10).

The association between anxiety and epilepsy results in the patients' greater demand for medical services (1). Nondrug treatments, such as psychotherapy, are strongly encouraged as the first-line treatment for epileptic patients (11). However, despite the high prevalence of anxiety in these patients, timely diagnosis and appropriate treatment have been neglected (12). Overall, many psychobehavioral therapies are aimed at the improvement of psychological wellbeing and convulsion control in epileptic patients. In this regard, behavioral approaches, cognitivebehavioral therapy, mindfulness-based cognitive therapy (MBCT), and physical interventions are widely used to help epileptic patients (13).

MBCT interventions are among third-generation cognitive behavioral therapies. Mindfulness is described as the use of a unique and targeted approach in the present moment without making any judgments (14). Mindfulness 
exercises activate an area of the brain, which creates positive emotions and has beneficial effects on the body's immune function (15). Over the past 3 decades, use of MBCT has been welcomed. The literature review showed that more than 70 scientific articles have been published on this type of therapy (16).

Exercises used in MBCT help increase self-awareness and self-acceptance of the patients (17). This type of therapy and exercise helps raise awareness about functioning of the mind and daily activities in the past and future and can help control awareness of thoughts, feelings, and gestures in every moment (18). It should be noted that mindfulness is not a technique or method, although many techniques and exercises are used during treatment. In fact, this type of therapy can be described as a way of understanding personal feelings.

As mentioned earlier, MBCT increases the awareness and understanding of people about the content of the mind. Therefore, this type of therapy is generally described as a way of perceiving and understanding (17). In addition, MBCT adds some elements of cognitive therapy, which help maintain concentration. Maintenance of concentration on individual thoughts is also employed for emotions and physical sensations (19). Therefore, considering the theoretical and research principles and the scarcity of information on the impact of MBCT on anxiety and self-efficacy in epileptic patients, we aimed to determine the effects of MBCT on these variables.

\section{Objectives}

The aim of the present study was to determine the efficacy of MBCT on self-efficacy and anxiety among epileptic patients.

\section{Methods}

In this experimental study, a pretest-posttest, controlgroup design with a 1-month follow-up was applied. The study population included all epileptic patients, referring to the healthcare centers of Kuhdasht, Iran during the study. The sample size was determined based on a pilot study, indicating a sample size of 15 for each group (20). Then, the inclusion and exclusion criteria were determined (Table 1 ) and evaluated using clinical interviews and Diagnostic and statistical manual of mental disorders (DSM-V) criteria.

The subjects were selected among epileptic patients, referring to healthcare centers of Kuhdasht. In case they met the inclusion criteria, they were randomly divided into 2 groups. The study procedure included evaluation of
Table 1. A summary of the Inclusion and Exclusion Criteria

\begin{tabular}{|ll}
\hline Exclusion Criteria & Inclusion Criteria \\
\hline $\begin{array}{l}\text { - Informed consent and desire to } \\
\text { participate in the study }\end{array}$ & $\begin{array}{l}\text { - Unwillingness or inability to } \\
\text { participate in meetings and } \\
\text { unwillingness to do the exercises }\end{array}$ \\
\hline $\begin{array}{l}\text {-Ability to participate in meetings } \\
\text { and collaborate on homework }\end{array}$ & $\begin{array}{l}\text { - Absence of more than } 3 \text { sessions in } \\
\text { the treatment process }\end{array}$ \\
\hline $\begin{array}{l}\text { - Diagnosis of epilepsy by a } \\
\text { neurologist }\end{array}$ & $\begin{array}{l}\text { - Receiving treatment or having } \\
\text { infections due to other physical or } \\
\text { psychological disorders intervening } \\
\text { with the results of the study }\end{array}$ \\
\hline $\begin{array}{l}\text {-Report of temporal lobe epilepsy } \\
\text { or grand mal seizures }\end{array}$ & $\begin{array}{l}\text { - Having cognitive dysfunctions } \\
\text { - A 5-year history of epilepsy } \\
\text { (minimum) }\end{array}$ \\
\hline $\begin{array}{l}\text { - Age range of 18-45 years } \\
\text { - Minimum education level of }\end{array}$ & $\begin{array}{l}\text { - Having symptoms of acute diseases } \\
\text { study difficult or almost impossible }\end{array}$ \\
\hline
\end{tabular}

the effectiveness of MBCT in increasing efficacy and reducing anxiety among epileptic patients, based on the pretest, posttest, and follow-up results.

First, 30 eligible subjects were selected among patients referring to healthcare centers of Kuhdasht to receive medication on specific dates at the mental health unit. Then, 30 sheets were prepared and distributed in the groups (15 A4 paper sheets per group). During the pretest, by using the general self-efficacy scale (GSES) and self-rating anxiety scale (SAS), the researcher individually asked each patient to choose one of the sheets. All the patients were randomly divided into 2 groups (A and B) and were randomly assigned to control and experimental (MBCT) groups.

The patients received MBCT at Fajr healthcare center of Kuhdasht by a therapist, who had passed the MBCT course and had the necessary expertise in this context. The intervention included 8 sessions (1 session per week), with each psychotherapy session lasting 1 to 2 hours. The posttest was administered in the final session, and follow-up was conducted during 1 month after therapy. The control group also received $\mathrm{MBCT}$ due to moral considerations after the study. The MBCT protocol is presented in Table 2. The data collection tools included demographic sheets, GSES, and SAS.

\subsection{Demographic Sheet}

The sample sheet included age, sex, educational level, and marital status of the patients. It was prepared and evaluated by the researchers. 
Table 2. A summary of Functional and Instructional Sessions of Mindfulness-Based Cognitive Therapy (MBCT)

\begin{tabular}{|c|c|}
\hline Session & Content \\
\hline First session: Automatic pilot & $\begin{array}{l}\text { Introduction of the automatic } \\
\text { guidance system/knowledge on how } \\
\text { to use present moment awareness of } \\
\text { bodily sensations, thoughts, and } \\
\text { emotions to reduce stress/practice of } \\
\text { eating raisins }{ }^{\mathrm{a}} \text {, giving feedback and } \\
\text { discussing the practice/3-minute } \\
\text { breathing, giving assignments for } \\
\text { the next week, and distributing } \\
\text { leaflets of the first session and } \\
\text { meditation CDs }\end{array}$ \\
\hline Second session: Facing obstacles & $\begin{array}{l}\text { Reexamination of body } \\
\text { workouts/giving feedback and } \\
\text { discussing body workout } \\
\text { examination/practicing breathing in } \\
\text { mindful meditation/distributing } \\
\text { leaflets of the second session and } \\
\text { meditation CDs }\end{array}$ \\
\hline $\begin{array}{l}\text { Third session: Kindness with } \\
\text { breathing and body and } \\
\text { awareness about breathing and } \\
\text { body movements }\end{array}$ & $\begin{array}{l}\text { Conscious sitting with awareness of } \\
\text { breathing (sitting meditation)/ } \\
\text { practicing 3-minute } \\
\text { breathing/distributing leaflets of the } \\
\text { third session and a videotape of yoga } \\
\text { practices }\end{array}$ \\
\hline $\begin{array}{l}\text { Fourth session: Learning how to } \\
\text { answer }\end{array}$ & $\begin{array}{l}\text { Reexamination of body workouts in } \\
\text { the hospital chapel/5-minute } \\
\text { practice of "seeing or } \\
\text { hearing"/repracticing the conscious } \\
\text { session with awareness of breathing } \\
\text { and body/distributing leaflets of the } \\
\text { fourth session and meditation CDs }\end{array}$ \\
\hline $\begin{array}{l}\text { Fifth session: Slow adjustment } \\
\text { with difficulties (attendance) }\end{array}$ & $\begin{array}{l}\text { Practicing breathing/repracticing } \\
\text { the conscious session (awareness of } \\
\text { breathing, body, sounds, and } \\
\text { thoughts)/explaining stress and } \\
\text { anxiety and identifying the } \\
\text { participants' reactions to stress and } \\
\text { anxiety/examining the effect of } \\
\text { awareness of pleasant and } \\
\text { unpleasant events on feelings, } \\
\text { thoughts, and bodily } \\
\text { sensations/practicing 3-minute } \\
\text { breathing/distributing leaflets }\end{array}$ \\
\hline $\begin{array}{l}\text { Sixth session: Thoughts are not } \\
\text { facts }\end{array}$ & $\begin{array}{l}\text { Practicing sitting meditation } \\
\text { (mindfulness of sounds and } \\
\text { thoughts)/distributing leaflets of the } \\
\text { sixth session and video tape No. } 4 \\
\text { among the participants }\end{array}$ \\
\hline Seventh session: Self-care & $\begin{array}{l}\text { Practicing mountain } \\
\text { meditation/sleep hygiene/repeating } \\
\text { exercises of the previous } \\
\text { session/listing enjoyable } \\
\text { activities/distributing leaflets of the } \\
\text { seventh session }\end{array}$ \\
\hline Eighth session: Going beyond fear & $\begin{array}{l}\text { Examining body workouts/overview } \\
\text { of the program/examining and } \\
\text { discussing programs }\end{array}$ \\
\hline
\end{tabular}

${ }^{\mathrm{a}}$ Object attention training.

\subsection{GSES}

GSES was designed by Maddux and Sherer and contains 17 items, rated on a 5-point Likert scale. High scores indi- cate high self-efficacy perception. Items $3,8,9,13$, and 15 of the scale are scored directly, while the rest of the items are scored in a reverse manner (21). Sherer et al. (1982) calculated the Cronbach's alpha to be 0.86 . Also, in terms of construct validity, Hossini Manesh (22) reported a correlation coefficient of 0.61 with the self-esteem scale. Also, reliability of the scale was evaluated in junior high-school students through Spearman-Brown method, showing a length of 0.76 and an unequal length of 0.76 (Guttman split half, 0.76). Additionally, analysis of the reliability of the scale indicated a Cronbach's alpha of 0.80. Hossini Manesh (22) also reported a Cronbach's alpha coefficient of 0.80 .

\subsection{SAS}

Zung designed SAS in 1970. This scale consists of 20 items, rated on a 4-point Likert scale. SAS is applicable for both individuals and groups, and respondents are asked to express how they felt or what they thought about over the last week. The reliability of the scale was measured to be 0.84 , using coefficient of coherence. The validity of the scale was measured at 0.71 , based on the application of 2 measures on more than 500 cases and measurement of Pearson's correlation coefficient (between 2 tests by Zank and Hamilton) (23). Also, the results of a study by Karami (24) showed a Cronbach's alpha of 0.84 and a coefficient of convergent validity of 0.75 , compared to Hamilton anxiety rating scale.

\subsection{Statistical Analysis}

For statistical analysis, descriptive statistics were measured and repeated measures analysis of variance was performed, using SPSS version 21. The protocol of MBCT is presented in Table 2 (18).

\section{Results}

The demographic characteristics of the study sample are presented in Table 3.

The mean and standard deviation (SD) of anxiety and self-efficacy in the pretest, posttest, and follow-up stages in the experimental and control groups are presented in Table 4.

As presented in Table 4 not only the mean and SD of self-efficacy increased from pretest to posttest, but also relative stability was observed in the follow-up phase. Also, the mean and SD of anxiety decreased from the pretest to posttest, and relative stability was reported in the followup phase.

In this study, statistical analysis of efficacy and anxiety scores in the experimental and control groups was performed, using multivariate analysis of covariance. In this 
Table 3. The Demographic Characteristics of the Subjects ${ }^{\mathrm{a}}$

\begin{tabular}{l|c|c|c}
\hline \multirow{4}{*}{ Gender } & Male & Control (N=15) & $\begin{array}{c}\text { Experimental } \\
(\mathbf{N}=\mathbf{1 5})\end{array}$ \\
\hline & Female & $4(26.7)$ & $12(80)$ \\
\hline \multirow{4}{*}{ Age, y } & 20 to 25 & $2(13.3)$ & $3(20)$ \\
\cline { 2 - 4 } & 26 to 30 & $4(26.7)$ & $2(13.3)$ \\
\cline { 2 - 4 } & 31 to 35 & $2(13.3)$ & $3(20)$ \\
\cline { 2 - 4 } & 36 to 40 & $5(33.3)$ & $2(13.3)$ \\
\cline { 2 - 4 } & 41 to 45 & $2(13.3)$ & $5(33.3)$ \\
\cline { 2 - 4 } & Eelow high & $7(46.7)$ & $7(46.7)$ \\
\hline \multirow{4}{*}{ Education } & High school & $6(40)$ & $7(46.7)$ \\
\cline { 2 - 4 } & Above high & $2(13.3)$ & $1(6.6)$ \\
\hline \multirow{4}{*}{ Marital status } & Married & $5(33.3)$ & $4(26.7)$ \\
\cline { 2 - 4 } & Single & $10(66.7)$ & $11(73.3)$ \\
\hline
\end{tabular}

${ }^{\mathrm{a}}$ Values are expressed as mean $\pm \mathrm{SD}$ or No. (\%).

analysis, the pretest scores were considered as a covariate, posttest and follow-up scores as dependent variables, and time as the moderating variable. Prior to the analysis, preassumptions about the model were investigated.

As can be seen in Table 5 the null hypothesis of homogeneity of variances in the 2 groups for self-efficacy and anxiety was confirmed. The variances in the 2 groups were equal, and there was no significant difference. Therefore, according to Levene's test results, we could conduct a multivariate analysis of variances in the research results.

The results of Mauchly's test for self-efficacy showed the homogeneity of covariance matrix $(\mathrm{P}=0.173$; Mauchly's $\mathrm{W} ; 0.878 ; \mathrm{Df}, 2)$. The results of multivariate analysis showed that time (pretest, posttest, and follow-up) was statistically significant in efficacy (partial eta squared, $0.841 ; \mathrm{P}<0.001$; $\mathrm{F}=$ 437.71; Pillai's trace, 0.841). Also, the interaction effect between group and time was significant (partial eta squared, 0.853; $\mathrm{P}<0.001 ; \mathrm{F}, 78.624$; Pillai's trace, 0.853).

Considering the significant difference between the experimental and control groups and the results presented in Table 3, the mean score of experimental group was higher than the control group in the posttest and followup phases. It can be concluded that the independent variable (MBCT) is effective in increasing self-efficacy.

The results of Mauchly's test for anxiety showed the homogeneity of covariance matrix ( $\mathrm{P}=0.386$; Mauchly's W, 0.932; Df, 2). The results of multivariate analysis showed the significance of time (pre-test, post-test, and follow-up) in anxiety (partial eta squared, 0.785; P < 0.001; F, 82.521; Pillai's trace, 0.859). Also, the interaction effect between group and time was significant (partial eta squared, 0.853; $\mathrm{P}<0.001 ; \mathrm{F}, 624.78$; Pillai's trace, 0.853) (Figures 1 and 2).

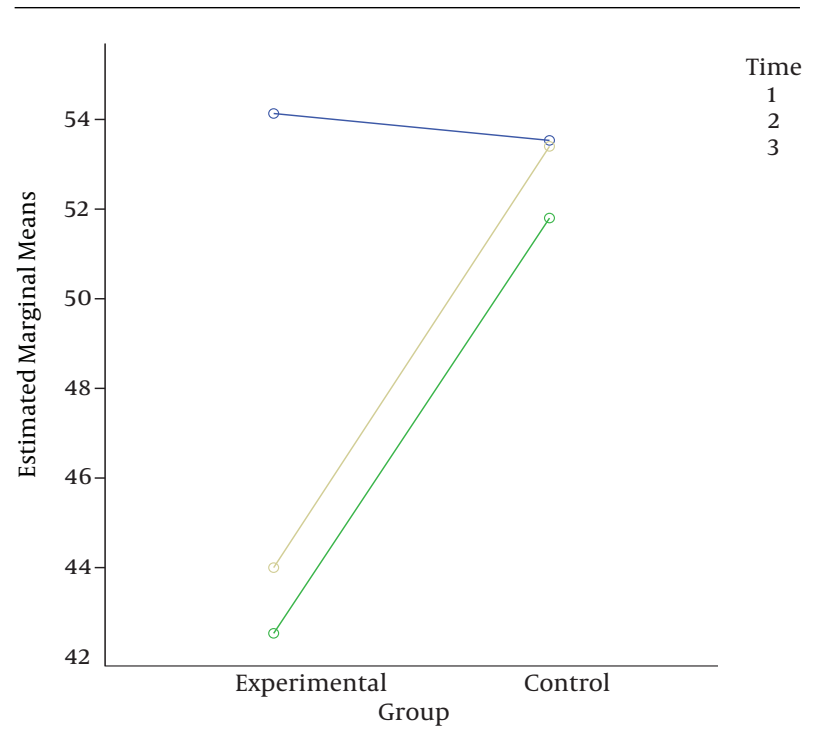

Figure 1. The Interaction Effect of Time and Group on Self-Efficacy

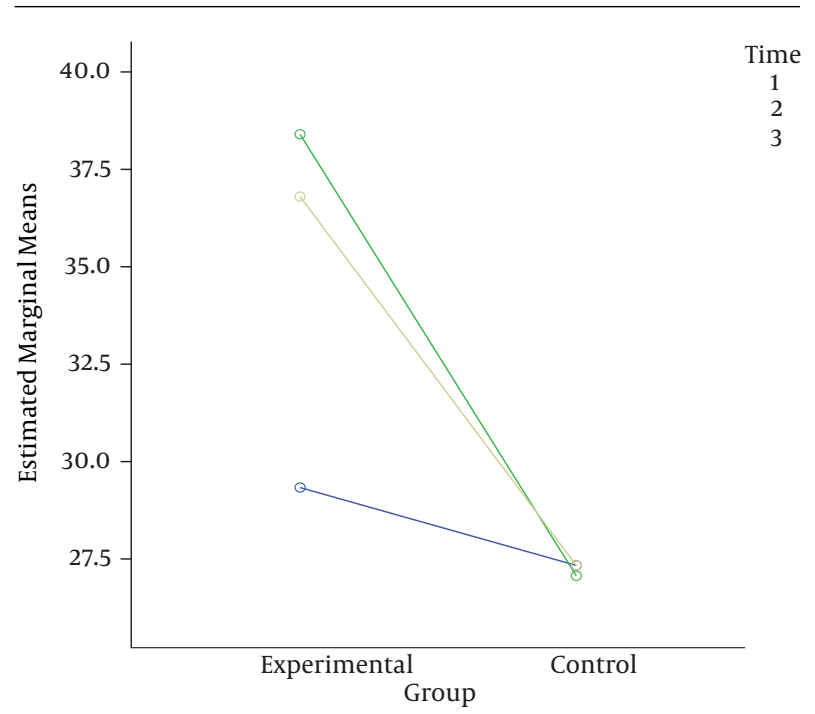

Figure 2. The Interaction Effect of Time and Group on Anxiety

\section{Discussion}

The purpose of the present study was to investigate the effects of MBCT on self-efficacy and anxiety in epileptic pa- 
Table 4. The Mean and Standard Deviation (SD) of Self-Efficacy and Anxiety in Patients with Epilepsy Over Time (Pretest, Posttest, and Follow-Up)

\begin{tabular}{lcccccc}
\hline Variables & \multicolumn{3}{c}{ Experimental $(\mathbf{N}=\mathbf{1 5})$} & & \multicolumn{3}{c}{ Control $(\mathbf{N}=\mathbf{1 5})$} \\
\cline { 2 - 7 } & Pretest & Posttest & Follow-Up & \multicolumn{2}{c}{ Pretest } & Posttest \\
\hline Self-efficacy & $29.33 \pm 4.54$ & $38.40 \pm 5.08$ & $36.80 \pm 5.17$ & $27.33 \pm 5.12$ & $27.07 \pm 4.43$ & $27.33 \pm 4.48$ \\
Anxiety & $54.14 \pm 8.10$ & $42.53 \pm 6.71$ & $44.01 \pm 7.85$ & $53.52 \pm 8.35$ & $51.80 \pm 7.21$ & $53.40 \pm 8.31$ \\
\hline
\end{tabular}

Table 5. Levene's Test Results on Homogeneity of Variances for Preassumptions in the Groups

\begin{tabular}{l|c|c|c|c|c}
\hline Variables & Stages & F & One Degree of Freedom & Two Degrees of Freedom & Significance Level \\
\hline \multirow{2}{*}{ Self-efficacy } & Posttest & 0.017 & 1 & 28 \\
\cline { 2 - 6 } & Follow-up & 0.021 & 1 & 28 \\
\hline \multirow{2}{*}{ Anxiety } & Posttest & 0.448 & 1 & 28 \\
\cline { 2 - 6 } & Follow-up & 0.015 & 1 & 28 \\
\hline \multirow{2}{*}{0.980} & & 28 \\
\hline
\end{tabular}

tients. Based on the findings, there was a significant difference between the groups in terms of self-efficacy and anxiety $(\mathrm{P}<0.001)$. Therefore, it can be concluded that MBCT increases self-efficacy and reduces the impact of anxiety symptoms in epileptic patients.

Researchers have used cognitive behavioral therapy to improve the quality of life of patients with epilepsy (25). In this regard, cognitive-behavioral therapy was applied in a previous study on epileptic patients with anxiety disorders to improve their symptoms (26). In another study, a cognitive behavioral intervention was applied to improve efficiency and self-management of epileptic patients. The results showed that treatment could be effective in improving self-efficacy (27).

Epilepsy in many cases is accompanied by psychiatric disorders, which can cause problems for the patients (28). Many studies have confirmed the association between epilepsy and anxiety disorders (29-33). In fact, the relationship between epilepsy and anxiety has attracted the researchers' attention to psychological therapy (34). Previous studies have supported the application of MBCT for epileptic patients to improve the symptoms of epilepsy and mental disorders, associated with epilepsy (eg, anxiety and depression). The present results are consistent with these findings (35-37).

Several studies have supported the impact of MBCT on anxiety $(38,39)$. Therefore, this type of therapy can be effective in reducing anxiety, associated with epilepsy. Furthermore, knowledge and understanding of physical, emotional, and mental aspects through MBCT can help reduce the symptoms of anxiety; consequently, this dynamic reduction improves the management of epilepsy.

Consistent with the present findings, previous studies have supported the impact of MBCT on the improve- ment of self-efficacy in patients $(40,41)$. Therefore, this type of therapy can be useful in improving self-efficacy among epileptic patients. Through improving self-efficacy, patients can better control their symptoms, review and evaluate their medication use, avoid seizures (through better management), develop a comprehensive personal care program, and finally manage their disease through selfcare. Also, the health benefits support the increased emotional processing, improved adjustment with chronic diseases and stress, improved quality of life and control over the affairs, and shaping of a different image of wellbeing, which naturally affects one's satisfaction in life (42).

MBCT affects one's beliefs and thoughts through different practices (eg, being in the present moment) and exercises (eg, concentration on the breath, body, and awareness). Moreover, it encourages the individual to have presence of mind, using various exercises which strengthen the memory. In these exercises, the person is encouraged to communicate his/her thoughts and feelings; this awareness in fact leads the person to be more in touch with him/herself and help reduce the symptoms of the disease. Therefore, according to this speculation, MBCT can be used for epileptic patients due to its effectiveness.

There are some limitations in the present study. The insufficient number of patients for the placebo group in the research design is one of these shortcomings. Therefore, integration of placebo groups or applied interventions is recommended in future studies. Furthermore, the small sample size of each group is another shortcoming of this study, which limits the generalizability of research results. In addition, some epileptic patients were unwilling to participate in the study, thereby affecting the generalizability of the findings to the study population. It is suggested to promote patient participation in training and psychother- 
apy sessions by emphasizing on the importance of mental health, along with medical treatments.

As mentioned earlier, this study had some limitations in terms of the generalizability of the results. Lack of control over the experimental and control groups regarding seizure frequency was another shortcoming; accordingly, it is suggested to control the number of seizures in future studies. Also, in this study, we had no control over the disease or study population, which was limited to patients with epilepsy in Kuhdasht. Therefore, one should be cautious in generalizing the results to epileptic patients with other diseases in other cities. Also, similar studies should be performed on specific types of epilepsy in samples selected from different cities.

\section{Acknowledgments}

We would like to thank all epileptic patients, who cooperated with the research team, patiently responded to the questions, and participated in the educational programs. We also extend our gratitude to the healthcare center of Kuhdasht and its personnel, who allowed us to perform this research and cooperated with us.

\section{Footnotes}

Authors' Contribution: Fakhri Tajikzadeh is the corresponding author and responsible for drafting and revision of the manuscript. Samaneh Mohamadpour was responsible for data acquisition, statistical analysis, and interpretation of data. Abdolaziz Aflakseir was responsible for the study concept and design.

\section{Funding/Support: None.}

\section{References}

1. Kaplan H, Sadock BJ. Synopsis of psychiatry. Baltimore: Wiliams and Wilkins; 2007.

2. Caplan R, Siddarth P, Gurbani S, Hanson R, Sankar R, Shields WD. Depression and anxiety disorders in pediatric epilepsy. Epilepsia. 2005;46(5):720-30. doi: 10.1111/j.1528-1167.2005.43604.x. [PubMed: 15857439].

3. Beyenburg S, Mitchell AJ, Schmidt D, Elger CE, Reuber M. Anxiety in patients with epilepsy: systematic review and suggestions for clinical management. Epilepsy Behav. 2005;7(2):161-71. doi: 10.1016/j.yebeh.2005.05.014. [PubMed:16054870].

4. Sung C, Muller VR, Ditchman N, Phillips B, Chan F. Positive Coping, Self-Efficacy, and Self-Esteem as Mediators Between Seizure Severity and Life Satisfaction in Epilepsy. Rehabil Res Policy Educ. 2013;27(3):15470. doi: 10.1891/2168-6653.27.3.154.

5. Brandt C, Schoendienst M, Trentowska M, May TW, Pohlmann-Eden $\mathrm{B}$, Tuschen-Caffier B, et al. Prevalence of anxiety disorders in patients with refractory focal epilepsy-a prospective clinic based survey. Epilepsy Behav. 2010;17(2):259-63. doi: 10.1016/j.yebeh.2009.12.009. [PubMed: 20075009]
6. Reilly C, Agnew R, Neville BG. Depression and anxiety in childhood epilepsy: a review. Seizure. 2011;20(8):589-97. doi 10.1016/j.seizure.2011.06.004. [PubMed: 21741277].

7. Smithson WH, Hukins D, Buelow JM, Allgar V, Dickson J. Adherence to medicines and self-management of epilepsy: a community-based study. Epilepsy Behav. 2013;26(1):109-13. doi: 10.1016/j.yebeh.2012.10.021. [PubMed: 23246201].

8. Dilorio C, Shafer PO, Letz R, Henry TR, Schomer DL, Yeager K, et al. Behavioral, social, and affective factors associated with selfefficacy for self-management among people with epilepsy. Epilepsy Behav. 2006;9(1):158-63. doi: 10.1016/j.yebeh.2006.05.001. [PubMed: 16798100].

9. Johnson EK, Fraser RT, Miller JW, Temkin N, Barber J, Caylor L, et al. A comparison of epilepsy self-management needs: provider and patient perspectives. Epilepsy Behav. 2012;25(2):150-5. doi: 10.1016/j.yebeh.2012.07.020. [PubMed: 23032121].

10. Wagner JL, Smith G, Ferguson P. Self-efficacy for seizure management and youth depressive symptoms: caregiver and youth perspectives. Seizure. 2012;21(5):334-9. doi: 10.1016/j.seizure.2012.02.009. [PubMed 22425424]

11. Shaikh MF, Arulsamy A. The impact of epilepsy on the manifestation of anxiety disorder. In J Nut Pharmacol Neur Dis. 2016;6(1):3. doi 10.4103/2231-0738.173783.

12. Fiest KM, Patten SB, Jette N. Screening for Depression and Anxiety in Epilepsy. Neurol Clin. 2016;34(2):351-61. doi: 10.1016/j.ncl.2015.11.003. [PubMed: 27086983] vii-viii.

13. Tang V, Michaelis R, Kwan P. Psychobehavioral therapy for epilepsy. Epilepsy Behav. 2014;32:147-55.

14. Segal ZV, Williams JMG, Teasdale JD. Mindfulness-based cognitive therapy for depression. Guilford Press; 2012.

15. Davidson RJ, Kabat-Zinn J, Schumacher J, Rosenkranz M, Muller D Santorelli SF, et al. Alterations in brain and immune function produced by mindfulness meditation. Psychosom Med. 2003;65(4):56470. [PubMed: 12883106].

16. Ludwig DS, Kabat-Zinn J. Mindfulness in medicine. JAMA. 2008;300(11):1350-2. doi: 10.1001/jama.300.11.1350. [PubMed: 18799450].

17. Baer RA. Mindfulness Training as a Clinical Intervention: A Conceptual and Empirical Review. Clin Psychol Sci Pract. 2006;10(2):125-43. doi: 10.1093/clipsy.bpg015.

18. Segal ZV, Williams JMG, Teasdale JD. Mindfulness-based cognitive therapy for depression: A new approach to relapse prevention. New York: Guilford; 2002

19. Williams JM, Teasdale JD, Segal ZV, Soulsby J. Mindfulness-based cog nitive therapy reduces overgeneral autobiographical memory in formerly depressed patients. J Abnorm Psychol. 2000;109(1):150-5. [PubMed: 10740947].

20. Delavar A. Research Methods in psychology and educational Sciences. Tehran: Edited Press; 2007.

21. Haghayegh AS, Ghasemi N, Neshatdoost HT, Kajbaf M, Khanbani M. Psychometric properties of Diabetes Management Self-Efficacy Scale (DMSES). Iran J Endocrinol Metab. 2010;12(2):111-95.

22. Hossini Manesh SZ. The mediating role of achievement motivation in the relationship between emotional creativity, self-efficiency and academic performance of high school female students. Semnan University Faculty of Psychology \& Education; 2014.

23. Kazemian S, Kalantar Hormozi A. Effectiveness of the self Differentiation Training in According to Bowen Theory on reducing Anxiety and increasing self-Confidence in High school students from divorced families. N Findings Psychol. 2013;7(22):63-72.

24. Karami D. Prevalence of procrastination among university students and its relationship with anxiety and depression. Thoughts Behav. 2009;4(13):25-34.

25. Caller TA, Ferguson RJ, Roth RM, Secore KL, Alexandre FP, Zhao W, et al A cognitive behavioral intervention (HOBSCOTCH) improves quality of life and attention in epilepsy. Epilepsy Behav. 2016;57:111-7. 
26. Blocher JB, Fujikawa M, Sung C, Jackson DC, Jones JE. Computerassisted cognitive behavioral therapy for children with epilepsy and anxiety: a pilot study. Epilepsy Behav. 2013;27(1):70-6. doi: 10.1016/j.yebeh.2012.12.014. [PubMed: 23376339].

27. Wagner JL, Smith G, Ferguson P, van Bakergem K, Hrisko S. Feasibility of a pediatric cognitive-behavioral self-management intervention: Coping Openly and Personally with Epilepsy (COPE). Seizure. 2011;20(6):462-7.

28. Rai D, Kerr MP, McManus S, Jordanova V, Lewis G, Brugha TS Epilepsy and psychiatric comorbidity: a nationally representative population-based study. Epilepsia. 2012;53(6):1095-103. doi: 10.1111/j.1528-1167.2012.03500.x. [PubMed: 22578079].

29. Munger Clary H, Hamberger MJ. Association of anxiety symptoms with epilepsy type and seizure localization. San Diego: American Epilepsy Society Annual Meeting; 2012.

30. Kanner AM, Barry JJ, Gilliam F, Hermann B, Meador KJ. Anxiety disorders, subsyndromic depressive episodes, and major depressive episodes: do they differ on their impact on the quality of life of patients with epilepsy?. Epilepsia. 2010;51(7):1152-8. doi: 10.1111/j.15281167.2010.02582.x. [PubMed: 20477847].

31. Stevanovic D, Jancic J, Lakic A. The impact of depression and anxiety disorder symptoms on the health-related quality of life of children and adolescents with epilepsy. Epilepsia. 2011;52(8):e75-8. doi 10.1111/j.1528-1167.2011.03133.x. [PubMed: 21692790].

32. Kanner AM, Barry JJ, Gilliam F, Hermann B, Meador KJ. Depressive and anxiety disorders in epilepsy: do they differ in their potential to worsen common antiepileptic drug-related adverse events?. Epilepsia. 2012;53(6):1104-8. doi: 10.1111/j.1528-1167.2012.03488.x. [PubMed 22554067].

33. Stefanello S, Marin-Leon L, Fernandes PT, Li LM, Botega NJ. Depression and anxiety in a community sample with epilepsy in Brazil. Arq Neuropsiquiatr. 2011;69(2B):342-8. [PubMed: 21625763].

34. Kanner AM. Anxiety disorders in epilepsy: the forgotten psychiatric comorbidity. Epilepsy Curr. 2011;11(3):90-1. doi: 10.5698/1535-751111.3.90. [PubMed: 21852871].
35. Baslet G, Dworetzky B, Perez DL, Oser M. Treatment of psychogenic nonepileptic seizures: updated review and findings from a mindfulness-based intervention case series. Clin EEG Neurosci. 2015;46(1):54-64. doi: 10.1177/1550059414557025. [PubMed: 25465435].

36. Tang V, Poon WS, Kwan P. Mindfulness-based therapy for drugresistant epilepsy: An assessor-blinded randomized trial. Neurology. 2015;85(13):1100-7. doi: 10.1212/WNL.0000000000001967. [PubMed: 26333801].

37. Walker ER, Obolensky N, Dini S, Thompson NJ. Formative and process evaluations of a cognitive-behavioral therapy and mindfulness intervention for people with epilepsy and depression. Epilepsy Behav. 2010;19(3):239-46. doi: 10.1016/j.yebeh.2010.07.032. [PubMed: 20833592].

38. Martlew J, Pulman J, Marson AG. Psychological and behavioural treatments for adults with non-epileptic attack disorder. Cochrane Database Syst Rev. 2014(2):CD006370. doi: 10.1002/14651858.CD006370.pub2. [PubMed: 24519702].

39. Hofmann SG, Sawyer AT, Witt AA, Oh D. The effect of mindfulnessbased therapy on anxiety and depression: A meta-analytic review. J Consult Clin Psychol. 2010;78(2):169-83. doi: 10.1037/a0018555. [PubMed: 20350028].

40. Peck KR, Smitherman TA, Baskin SM. Traditional and alternative treatments for depression: implications for migraine management. Headache. 2015;55(2):351-5. doi: 10.1111/head.12521. [PubMed: 25644990].

41. Miller CK, Kristeller JL, Headings A, Nagaraja H, Miser WF. Comparative effectiveness of a mindful eating intervention to a diabetes self-management intervention among adults with type 2 diabetes: a pilot study. J Acad Nutr Diet. 2012;112(11):1835-42. doi: 10.1016/j.jand.2012.07.036. [PubMed: 23102183].

42. Grossman P, Niemann L, Schmidt S, Walach H. Mindfulness-based stress reduction and health benefits. A meta-analysis. J Psychosom Res. 2004;57(1):35-43. doi: 10.1016/S0022-3999(03)00573-7. [PubMed: 15256293]. 